\title{
LA MUERTE DOMADA EN LA OBRA POÉTICA DE EFRAÍN BARQUERO
}

\author{
THE TAMED DEATH IN THE POETIC WORK OF EFRAÍN BARQUERO
}

\author{
Sergio Pizarro Roberts \\ Universidad de Playa Ancha, Valparaíso \\ Chile \\ sergioto.pizarro@gmail.com
}

\begin{abstract}
Resumen: Dentro de las variadas temáticas que aborda la obra poética del chileno Efraín Barquero, en este trabajo se sistematiza la perspectiva metafísica al interior de un corpus de obras sugerido. A través de dicha mirada se advierte una realidad concebida al interior del discurso barqueriano que se configura como la mancomunión ancestral integrada por vivos y muertos, en donde estos últimos activan su participación en el texto en calidad de fantasmas o figuras espectrales. Esta reformulación prosopopéyica de la muerte, producto de una cosmovisión panteísta, rehúye los postulados de una fe trascendente y se traduce en una inmanencia que, si bien en los inicios de la obra barqueriana afecta solamente al clan de los antepasados del hablante, en su obra tardía termina asumiendo un carácter universal. Esta hipótesis de lectura, que propone una apertura epistémica de la muerte en Barquero, se obtiene como resultado de la combinación teórica de la racionalidad poética instaurada por María Zambrano y el carácter fundante que Gianni Vattimo confiere a la poesía, junto a la resemantización de la muerte que plantea Emmanuel Lévinas.
\end{abstract}

Palabras clave: muerte, fantasmas, antepasados, inmanencia, panteísmo.

\begin{abstract}
Within the various themes addressed by the poetic work of Efrain Barquero, this article focuses on Barquero's metaphysical perspective systematized by the poet in the selected works analyzed here. This Barquerian poetic metaphysics is configured as the ancestral unification of the living and the dead, where the latter activate their presence in the texts as ghosts, or spectral figures. This prosopoeic reformulation of death, a result of a pantheistic worldview, avoids the postulation of a transcendent faith, and instead of it relies on an immanence that only affects the speaker's clan of ancestors in the early works of Barquero. In his latest works this particular situation assumes a universal dimension. The reading hypothesis, which proposes an epistemic reworking about death in Barquero, is justified as a result of the theoretical combination of poetic rationality established by María Zambrano and the founding
\end{abstract}


character that Gianni Vattimo gives to poetry, together with the resemantization of the death posed by Emmanuel Lévinas.

Keywords: death, ghosts, ancestors, immanence, pantheism.

Recibido: 17/07/2020. Aceptado: 21/01/2021.

Qi hemos de constatar la dificultad que desde el pensamiento de Nietzs$\checkmark$ che en adelante supone para el lenguaje asir la realidad, la muerte se constituye como un verdadero desafío para cualquier disciplina que tenga en la palabra el sustento de su expresión por tratarse, peor aún, de una no realidad. En ese contexto de desfase entre lenguaje y realidad, la razón instrumental que caracteriza el pensamiento de Occidente se vuelve insuficiente y ve mermados sus presupuestos de control cuando surgen nuevas consignas epistemológicas que avalan otro tipo de racionalidades a través de las cuales se puede comprender mejor esta enrevesada existencia. Se produce, en consecuencia, una inversión en el orden de los valores y la apreciación peyorativa de una irracionalidad estéril se ve reemplazada por el de una racionalidad deslegitimada en su afán de verdad.

Cuando los discursos cientificistas evidencian su contrariedad ante lo informulable de la muerte, la pregunta sobre el misterio tanatológico se desvía hacia la poesía que contiene los mecanismos de una retórica oblicua, construida principalmente sobre la base de símbolos y metáforas. De esta manera, la desconfianza icónica de Platón pierde fuerza cuando la filósofa María Zambrano, heredera del ratio-vitalismo ortegiano, en Filosofía y poesía (1939) acuña, por su parte, el concepto de "razón poética" mediante el cual busca la dimensión sagrada de lo real a través de la recuperación de la unidad epistémica entre religión, poesía y filosofía. Para ella el relato de la historia de Occidente consiste en aplaudir la separación entre filosofía y religión, y sugiere que la crisis de nuestra modernidad se enraíza en esa primigenia y determinante escisión.

En esa misma dirección podemos situar al italiano Gianni Vattimo cuando señala que "el carácter inaugural de la poesía y del arte es concebido siempre a la luz del hecho de 'fundar', es decir, de presentar posibles mundos históricos alternativos del mundo existente" (1987: 63, cursiva en el original). Presenciamos la necesidad contemporánea, insiste Vattimo, de 
desenmascarar a un sujeto moderno obnubilado de su propia subjetividad que se "resiste a la peculiar movilidad, inseguridad y permutabilidad de lo simbólico" (1987: 29).

Según estos autores, entonces, la razón y el lenguaje poéticos coparticipan con el discurso filosófico en el afán que aspira a una mejor comprensión de esta realidad en permanente mutación, erigen la posibilidad de otros mundos mediante una percepción alternativa de la existencia e intentan reconfigurar la constancia de la muerte mediante una simbología que la resignifique. Esta perspectiva se confirma nuevamente en el pensamiento de Emmanuel Lévinas cuando contradice el clásico Sein zum Tode (ser para la muerte) de Martín Heidegger en Ser y tiempo (1927) con su antagónico "ser contra la muerte" en Totalidad e infinito (1961). Contrario a la postura agnóstica de Heidegger, prefiere entender la muerte como una apertura a lo desconocido más que como sinónimo de la nada. La reductiva designificación tanatológica heideggeriana se amplía de este modo en un abanico de posibles resemantizaciones de la muerte. En los cursos reunidos en Dios, la muerte y el tiempo, Lévinas aventura algunas posibilidades que son consecuencia de la negativa a "que se pueda considerar la muerte como certeza, ni tampoco que tenga el significado de anonadamiento" (1993: 20-21). En una apretada síntesis en que, por falta de espacio, omito sus respectivas explicaciones, podemos rescatar algunas resignificaciones levinianas de la muerte como "partida sin retorno" (1993: 20) o como "ambigüedad o enigma" (1993: 25). "Es preciso preguntarse [dice Lévinas] si no nos encontramos, aquí, en una dimensión del sentido donde se piensa en un más allá del ser y la nada, incluso si aquí adquiere sentido otra dimensión del pensamiento, una dimensión que no es el silencio sugerido por Fink" (1993: 112).

Esta apertura epistémica de la muerte en Lévinas confiere uno de los posibles accesos a través del cual podríamos comprender la poética de ultratumba del poeta Efraín Barquero (1931-2020), un referente obligatorio en la poesía chilena como miembro de la llamada generación del '50. La temática de la muerte, sin embargo, a pesar de ser un tópico fundamental en su poética, comparte espacios con otros intereses estéticos, quizá de mayor importancia en su trayectoria artística que los estrictamente metafísicos, como es el caso de su poesía testimonial y política (La piedra del pueblo, 1954; El poema negro de Chile, 1974; Bandos marciales, 1974), de su poe- 
sía infantil (Poemas infantiles, 1965; El viejo y el niño, 1992), de la poesía musical y popular (Maula, 1962) y sus poemas de amor (La compañera, 1956).

Con respecto a su inquietud metafísica rescato de la escasa bibliografía crítica que se tiene hasta ahora sobre la obra de Barquero, dos interesantes comentarios que pueden servir como punto de partida para entrar en su poética escatológica. El de Fernando Alegría que dice:

su poesía vuelve una y otra vez a considerar las sombras de los antepasados, el monumento invisible del padre en el corazón campesino, la mesa puesta para una cena fantasmal que se repite lentamente a través de las edades con la persistencia de la muerte y de los frutos en verano (1962: 51-52).

Y el comentario de Marcelo Rioseco, referido al orden mítico y preliminar del alcance poético de Barquero, y a "la dimensión metafísica de su poesía [que] lo conduce por los caminos de la reflexión y la imagen esencial" (1999: 20-21). Por lo tanto, la mención de los antepasados, el carácter fantasmal y la dimensión metafísica de su obra son tres vectores alrededor de los cuales pretende girar mi hipótesis de lectura como resultado de un análisis progresivo y diacrónico del corpus integrado por las siguientes siete publicaciones del poeta: La piedra del pueblo (1954), Enjambre (1959), El pan del hombre (1960), El regreso (1961), Epifanías (1970), Mujeres de oscuro (1992) y El pan y el vino (2008).

La piedra del pueblo (1954) es un libro que con sus cincuenta poemas representa la tragedia del pobre en Chile, principalmente en los suburbios marginales de la ciudad de Santiago, y que plasma su denuncia en una estela de desasosiego, resistencia y esperanza al invertir estéticamente la simbología cristiana hacia referentes marxistas. Por otra parte, al leer el prólogo que redacta Pablo Neruda para esta entrega sorprende corroborar cómo disputas históricas e ideológicas de la tradición poética chilena se mantienen inalterables a lo largo del tiempo. Me refiero específicamente a los autoproclamados poetas de la claridad que en la antología de Tomás Lago, de 1938, se contraponen a los llamados poetas oscuros o herméticos, y que integran la antología de Eduardo Anguita y Volodia Teitelboim, de 1935. Pablo Neruda, en el referido prólogo confirma la vigencia de esa convivencia en disputa cuando adscribe tácitamente a la postura de la cla- 
ridad y aplaude a un joven Barquero en los siguientes términos: "[e]n este minuto en que los oscuros se oscurecen hasta desaparecer llega a nosotros Efraín Barquero, recibiendo en su fino rostro y devolviéndola en su canto, la claridad del pueblo" (1954: 7).

Años después, Barquero revela en Arte de vida, su autobiografía:

deseaba curarme a toda costa de esto que había experimentado, de esto que era -a pesar de haber tenido una infancia limpia y, en cierto modo, feliz- "mi propia vida", la grande, la terrible, la irreversible vida, la que quieren transformar las religiones y las ideologías, de las cuales he visto después, como en el caso del marxismo, conquistas fundamentales, conquistas que serán siempre el punto de partida en la redención de los seres humanos (1971: 70, énfasis adicional).

En esta declaración se reflejan claramente las dos fuentes culturales de las que se nutre la poética metafísica de Barquero. Por un lado la visión religiosa del cristianismo y por otro, aunque sea inicialmente paradójico, la visión marxista. Gran número de poetas chilenos que desarrollan su obra en la primera mitad del siglo XX, de alguna manera, reflejan en su trabajo las lecturas de La Biblia y, en particular, el énfasis soteriológico o salvífico del Nuevo Testamento, es decir, la preocupación por la redención de los seres humanos gracias a la fe en la continuidad del ser basada en una escatología trascendente. Marx adecua la teleología salvífica que caracteriza al discurso cristiano y traduce su simbología basado en lo que en los estudios contemporáneos de teología se anuncia como una escatología intramundana al rehuir de una fe trascendente.

A pesar del prólogo de Neruda, entonces, la claridad marxista de Barquero va a verse oscurecida metafísicamente por el desarrollo de una poética heterodoxa y su particular representación de la muerte. Sin embargo, una escritura juvenil no podía evitar el asomo de contradicciones que luego desaparecen en obras posteriores. En efecto, en dos poemas de La piedra del pueblo declara explícitamente su ateísmo, especialmente en "Dios mal disfrazado" y en un tercer poema, "Armonía vital", se inscribe entre los llamados poetas de la claridad al recitar: "[q]uiero hablar de lo más simple y necesario / en la forma más clara y en pocos renglones // [...] yo soy claro y esencial, / [...] y no me pierdo en abstracciones ni me hundo en la muerte" (1954: 119, énfasis mío). La primera contradicción estriba en la compara- 
ción con el verso "siento gritar junto a mí a todos los muertos", del poema "No puedo callar" (1954: 63). Lo insólito del verso -al representar a un hablante vivo que escucha a los muertos- es el primer indicio en la obra de Barquero de una reformulación tanatológica que altera el equilibrio semántico de la dicotomía vida/muerte; y doblemente, es indicio, a su vez, de una estética que continúa, tímidamente en esta primera publicación, una larga tradición prosopopéyica en la literatura al recurrir a figuras espectrales y fantasmales que luego desarrollará cabalmente en su itinerario creativo. Una segunda contradicción menos literal lo constituye el seudónimo que elige el ciudadano Sergio Efraín Barahona, provocando una inevitable alusión a Caronte, el ‘barquero’ del Hades que en la mitología griega guiaba las sombras errantes de los difuntos por el río Aqueronte, con lo cual se avizora un hablante que sí se hundirá en la muerte o que al menos atisbará con curiosidad en el más allá. Prueba de ello es la publicación de Enjambre, cinco años después, en 1959.

De esta nueva entrega, dividida en dos secciones, destaco para esta investigación la primera, titulada decidoramente "Estirpe". Del tono combativo anterior el hablante traslada su discurso hacia los recuerdos de infancia. La evocación de una estirpe, en el título de la sección, va en íntima armonía con el título del libro en el que se utiliza la noción apícola del enjambre como una metáfora para representar a la familia y los antepasados; se da un giro desde el enfoque urbano hacia una representación bucólica y taciturna del campo, y en este intimismo ancestral y campesino no se perciben arengas anti-metafísicas sino, al contrario, aumentan significativamente las menciones de la muerte. Entran definitivamente en escena las figuras fantasmales de los ascendientes: el padre, la madre, y los abuelos. En poemas como "Granero", "Fogón” y "La encomienda del ausente" se confirma la inserción de este universo paralelo en lo cotidiano del relato y toma cuerpo la reflexión de que en la poesía, según Lévinas, adquiere sentido otra dimensión del pensamiento o una dimensión del sentido donde se piensa en un más allá del ser y la nada. En este último poema se lee:

Y el ausente, rodeado de estos frutos de sus ríos y sus bosques, vuelve a cantar como cuando los días eran buenos, había muchas crías y mucha leña cortada en el granero. El ausente vuelve a sentir las manos de la madre en su oscura vida, como cuando ella se sentaba al atardecer, en la puerta de la casa, con el vellón de las ovejas nuevas en la falda. // En- 
tonces todo se podía predecir: había grano y calor para todo el invierno (1959: 50).

Lo particular en la animación de estos seres sin vida o, en otras palabras, de esta reformulación prosopopéyica de la muerte, es que adquiere un sentido vitalista. Esta aparente paradoja se resuelve al comprender la interacción de los ancestros en su dimensión espectral como el fundamento indispensable para la continuidad cíclica de la vida, en la que participan tanto los vivos como los muertos en un engranaje metafísico. Según el poema, cuando se toman en consideración a los ausentes "todo puede predecirse" en un mecanismo agrícola de muerte y germinación continua, y que comprende a la realidad en términos panteístas. En el poema "El árbol tutelar" se advierte esta misma filiación:

Tierra de fruto más grande que el amor y más ancha que la muerte, única casa de los míos, donde los muertos siguen ayudando a los que permanecen de pie sobre los surcos, y donde estos últimos van a veces a preguntar por un injerto o un almácigo a los que yacen enterrados, y se quedan por un tiempo. ¿Cuánto tiempo? Quién sabe. Aquí la muerte y la vida se confunden en la gran fertilidad, en el perfume de las flores, en el estruendo del río. Y la eternidad es algo corriente y cercano, como una herramienta guardada en un sitio seguro, o el resplandor de la primavera que parece regresar de tan cerca (1959: 53-54).

El panteísmo (del griego pan, todo y Theos, Dios), en los términos que explica Ferrater Mora, es la creencia, doctrina o pensamiento que concibe al mundo y a Dios como sinónimos. Esta corriente monista de pensamiento, a diferencia de la dualista que distingue entre Dios y su creación (creador/ser creado), postula "que no hay ninguna realidad trascendente y de que todo cuanto hay es inmanente" (1951: 363). El panteísmo admite dos variantes: aquella que considera a la naturaleza y al mundo como emanación de Dios, según la cual, la realidad divina es la única verdadera y a ella se reduce el mundo, y la otra, en cambio, que concibe como única realidad verdadera a la naturaleza y en que, a la inversa, Dios se reduce a ella. La diferencia entre ambas es que la primera versión cree en una jerarquía superior de Dios, por lo que puede considerarse como panteísmo teísta, en cambio, la segunda no cree en dicha jerarquía metafísica por lo que suele denominarse panteísmo ateo o naturalista. El ideario poético de 
Barquero asume una percepción de la existencia más cercana al panteísmo ateo o naturalista y no representa a la muerte como el destino hacia el cual eventualmente trasciende cada ser en forma individual. La continuidad del ser en la poética de Barquero, en verdad, se despliega después de la muerte en figuras espectrales que, junto a los vivos, forman una mancomunión ancestral dentro de una realidad inmanente y común. Una reformulación prosopopéyica y panteísta de la muerte, que altera los límites semánticos en su relación dicotómica con la vida.

Esta desacostumbrada percepción de la existencia se despliega cómodamente en un texto poético y ese es el aporte que celebra Vattimo, citado más arriba, cuando reconoce la potencial capacidad epistémica de la poesía para ampliar los rangos de la realidad: su carácter inaugural e idoneidad para fundar posibles mundos alternativos al existente, y que vuelve a confirmarse en 1960 con una nueva publicación de Barquero: El pan del hombre. Vale la pena resaltar que Enjambre (1959), El pan del hombre (1960) y El regreso (1961) conforman una secuencia necropoética con tres intensas publicaciones sucesivas que no se vuelve a repetir en el itinerario estético del autor.

El título publicado en 1960 lo compone la reunión de trece poemas en el que todos, salvo dos excepciones, aluden al tema de la muerte. Desde los primeros versos del poemario el hablante barqueriano nos vuelve a inmiscuir en la intimidad de sus antepasados, mediante una particular cosmogonía en la que se repite la convivencia metafísica de vivos y muertos al interior de un clan familiar:

[y] la memoria que tenemos de los muertos, / se nos convierte en gozo blanco. / [...] es mi pasado o mi futuro, / es mi alimento o son mis huesos, / es mi padre cubierto en su mortaja / [...] Y esa voz que me llamaba desde el fondo de la casa (1960: 9-10, 12).

Nuevamente participan figuras espectrales que, en ocasiones, detentan una vaga relación de parentesco con el hablante. Estas figuras fantasmales, sin embargo, no se articulan estéticamente bajo el acostumbrado matiz de lo lúgubre, lo tétrico o lo siniestro, sino con el aura solemne de un rito ancestral. Al igual que en la publicación anterior, participan con un paradójico sentido vitalista que confirma la reformulación prosopopéyica y panteísta de la muerte a través, por ejemplo, de los siguientes versos: “[d]e 
nuestros cuerpos surgen otros cuerpos, / que corren por la playa desnuda y remota. / Y nos miran con su rostro único, / donde se confunden todos los demás: / el rostro de la infancia perdida / y el de la madurez se transparentan" (1960: 16-17). En el extracto, la multiplicidad de cuerpos representa el todo panteísta que los agrupa en un cuerpo y rostro únicos (incluido el del hablante) y en el que la infancia perdida se hace presente al fusionarse con el tiempo de madurez, creando una sensación de inmanencia en que la continuidad del ser no se prolonga, dentro de un continuum de tiempo lineal, en una trascendencia de ultratumba, sino que todo lo vivo y lo muerto sucede simultáneamente mediante la conjunción instantánea de dos dimensiones aparentemente incompatibles. "[E]s la hora de penetrar en el destiempo" (1960: 66) dirá el hablante con elocuente precisión estética en un poema posterior. Una noción, a su vez, que debe ser comprendida a la luz de una razón poética en los términos que explica María Zambrano:

La cosa del poeta no es jamás la cosa conceptual del pensamiento, sino la cosa complejísima y real, la cosa fantasmagórica y soñada, la inventada, la que hubo y la que no habrá jamás. Quiere la realidad, pero la realidad poética no es sólo la que hay, la que es; sino la que no es; abarca el ser y el no ser en admirable justicia caritativa, pues todo, todo tiene derecho a ser hasta lo que no ha podido ser jamás (1993: 22).

El tratamiento de la muerte en Barquero, según lo visto hasta ahora entonces, supone una racionalidad poética que instaura una manera distinta de comprender la realidad. En efecto, como resultado de la híbrida combinación entre cristianismo y marxismo, y la común inspiración soteriológica que los caracteriza (ultramundana e intramundana, respectivamente), se configura una estética fantasmagórica que confina nuestra tradicional percepción de la muerte y la reemplaza por una corriente de pensamiento panteísta, una cosmovisión inmanente, esencialmente colectivista, que entiende la realidad como la compleja unidad en que todas las partes son, a la vez, el todo indisoluble e indivisible. Estamos, entonces, ante una poética que descarta toda pretensión individualista de comprender la existencia y en que la esperanza en la continuidad del ser, o su particular inspiración soteriológica, debe entenderse sólo en cuanto a su carácter colectivo. Dicha continuidad opera solamente en la regeneración perpetua del todo mediante la reintegración cíclica de sus partes. En concreto, esta poética escato- 
lógica heterodoxa plantea que la existencia de un sujeto individualmente considerado carece de sentido si no es concebida dentro del conjunto de su especie.

En este punto de la investigación interesa destacar que la mirada política de la existencia proyectada por el poeta y la perspectiva metafísica, que según nuestra hipótesis plantea una resignificación de la muerte, están en íntima armonía, con lo cual se refleja una cosmovisión conceptualmente coherente. Esta particular calidad de la poética barqueriana la detecta lúcidamente Federico Schopf en su introducción a la versión de 1971 de La compañera (obra con diversas reediciones), cuando indica la dirección hacia la cual se orienta la estética del poeta de Piedra Blanca:

[U]na visión del hombre en que éste no pertenece propiamente a su singularidad y al tiempo, sino a la especie, en cuya asunción puede plenificar su vida y otorgarle un sentido. // Justamente, la asunción de la vida al nivel de la especie otorga un nuevo sentido a la vida individual: ella no está más interrumpida por la muerte: su esfuerzo se incorpora al esfuerzo de todos desde la más lejana humanidad, la vida se sume en las estructuras que superan el tiempo (1971: 16) ${ }^{1}$.

Y continuando la secuencia necropoética, al año siguiente, en 1961, el autor de La compañera publica El regreso, un texto breve que incluye un sólo poema dividido en veintiún secciones y que en una primera lectura se configura básicamente como el diálogo entre el hablante y su padre muerto que ha regresado espectralmente. Aquí se produce un quiebre importante al plasmarse, por primera vez en la trayectoria poética de Barquero, una comunicación verbal entre vivos y muertos que afina la posibilidad conectiva de dos dimensiones inicialmente incompatibles profundizando, con ello, la sensación de inmanencia provocada gracias a la racionalidad poética que menta Zambrano. Esta inédita interrelación dialógica en la obra poética de Barquero genera el destiempo en el que se confunden las categorías de lo vivo y lo muerto, todo lo cual se aprecia, a vía de ejemplo, en esta clásica cita: “-Hijo, ¿̇quién es esa niña que nos mira? / -Mi madre, vuestra espo-

\footnotetext{
${ }^{1}$ Esto pone en entredicho el supuesto carácter evasivo con el que se ha solido calificar a la poesía metafísica en la historiografía literaria chilena, y de la cual reniega inicialmente Barquero.
} 
sa” (Antología, 2000: 107). Y volvemos a citar a María Zambrano:

El poeta saca de la humillación del no ser a lo que en él gime, saca de la nada a la nada misma y le da nombre y rostro. El poeta no se afana para que de las cosas que hay, unas sean, y otras no lleguen a este privilegio, sino que trabaja para que todo lo que hay y lo que no hay, llegue a ser. El poeta no teme a la nada (1993: 22-23).

Un segundo verso de El regreso que conviene destacar es el que dice: "[p]ero hay un niño que juega con los muertos" (2000: 114). Esta simple y gráfica oración, inicialmente perturbadora, puede ser vista como la representación apacible a través de la cual el hablante intenta referirse al tema de la muerte; su aspiración de “domar la muerte”, en los términos que acuña Philippe Ariès. En El hombre ante la muerte el historiador francés sostiene que el sujeto moderno ha desterrado a la muerte de la vida cotidiana:

La actitud antigua en que la muerte está a la vez próxima, familiar, y disminuida, insensibilizada, se opone demasiado a la nuestra, en que causa tanto miedo que ya no osamos decir su nombre. // Por eso, cuando llamamos a esta muerte familiar la muerte domada, no entendemos por ese término que fuera antaño salvaje y que luego haya sido domada. Queremos decir por el contrario que hoy se ha vuelto salvaje mientras que antes no lo era. La muerte más antigua estaba domada (1992: 32)².

En ese entendido el Ubi sunt para la cosmogonía del sujeto barqueriano deja de ser una pregunta acuciante. Su poética irrumpe en la simbología de ultratumba del sujeto moderno, intercede en la tenebrosidad del misterio tanatológico absolutamente fuera de control, y promueve la domesticación

${ }^{2}$ Ariès indica: “[a]proximadamente en el siglo XIII, y al mismo tiempo que el velatorio, el duelo y el cortejo se convirtieron en ceremonias de Iglesia, organizadas y dirigidas por hombres de Iglesia [clericalización de la muerte]; había ocurrido algo que puede parecer insignificante, y que sin embargo pone de manifiesto un cambio profundo del hombre ante la muerte: el cuerpo muerto, antiguamente objeto familiar y figura del sueño, posee desde ahora un poder tal que su vista se vuelve insostenible. Durante siglos, será apartado de la vista, disimulado en una caja, bajo un monumento, donde ya no es visible. La ocultación del muerto es un gran acontecimiento cultural" (1992: 145). En El regreso, Barquero retrata el cuerpo muerto del padre, precisamente como objeto familiar y figura del sueño, desnudo sobre la mesa del comedor en vez de oculto adentro de una caja; una puesta en escena premoderna que refleja la inspiración de una muerte domada. 
de la muerte (que se encuentra en estado salvaje) mediante un discurso que relativiza la fugacidad de la vida, lo que viene a explicar, en parte, el carácter esperanzador de esta obra que la crítica ha resaltado3.

Diez años después de la comentada trilogía metafísica sesentera de Barquero se publica, en 1970, Epifanías, dividida en dos secciones. La primera, que está más explícitamente conectada con el punto de vista de esta investigación, se divide, a su vez, en 16 "temas" y desde el primero de ellos se retoma la densidad temática de la muerte mediante la renovada convivencia prosopopéyica de vivos y muertos. Tres versos nos sirven de ejemplo: "adentro de otros viviremos, cada vez más adentro / cómo al partir un fruto creo prolongar mi nacimiento. / [...] Extraña es esta casa cuya sombra nos fecunda" (1970: 10). Versos elocuentes que no ameritan mayores comentarios ya que reinciden en la idea de un cuerpo único en el que la humanidad nace y renace entre sombras fantasmales a través de un misterioso proceso de fecundación y germinación continuas.

Tanto en la primera como en la segunda sección del libro, la intensidad provocada por el mayor contacto con la dimensión de ultratumba amplía el horizonte de la realidad verbal del hablante. La tonalidad oracular y semihermética es producto de una sintaxis que se estructura a través de versos con conexiones semánticas más distanciadas y que generan nuevamente la sensación de destiempo que caracteriza la estética metafísica de esta obra barqueriana:

\footnotetext{
${ }^{3}$ Juan Villegas, por ejemplo, sostiene que Barquero "rechaza el tono angustiado o desolado de los anteriores [Arteche y Lihn] y opta por uno de mayor esperanza" (1980: 71); otro tanto hace Federico Schopf en su prólogo a La compañera cuando resalta "el carácter positivo y esperanzado que asume la obra de Barquero frente, por ejemplo, a la necesidad permanente de confirmar una visión trágica de la existencia que caracteriza a la poesía de Enrique Lihn y la transforma en vehículo de escepticismo, o frente a la nostalgia por un mundo definitivamente perdido que caracteriza a la poesía de Jorge Teillier" (1971: 7); o Pedro Lastra que en la solapa de Maula comenta: "[l]ejos de la efusión romántica, que se alimentó por muchos años de sombra y de lágrimas, este libro nos ayudó a descubrir el maravilloso juego de la relación humana fundamental, sostenida ahora en la alegría y en la esperanza" (1962); y finalmente Naín Nómez que en el prólogo a la Antología de Barquero del año 2000 alude a "la nostalgia por una armonía perdida, que en Barquero al contrario de los láricos, no se convierte en ruptura, angustia o incompletitud, sino que se arraiga en la tierra o la piedra para renovarse y renacer de nuevo" (2000: 9) (los tres énfasis de 'esperanza' son míos).
} 


\begin{abstract}
El mundo es mi invocación
yo vivo una vida más grande que mis límites

toda flor minúscula en mí quiere completarse

una gota no puedo recordar, sí todo el océano

un detalle se me borra para mostrarme todo el cielo

una estación encuentra su vacío colmado

un hombre crea otro donde cabe íntegro

el mundo de mi padre es un mundo alternado

estamos todos a la vez en estas piedras

sólo que vivimos una parte de nosotros (1970: 28).
\end{abstract}

No solo este fragmento seleccionado sino todo el conjunto de Epifanías transparenta una corriente panteísta de pensamiento y, hasta donde llegan mis fuentes, Naín Nómez lleva el mérito de ser el primer crítico que aplica tal calificación en el prólogo que escribe para la Antología de Efraín Barquero, publicada el año 2000. En este imprescindible rescate, especialmente por su difusión entre generaciones más jóvenes de lectores, la introducción de Nómez rotula al hablante de Epifanías compenetrado "con una naturaleza trascendente" (2000: 15). Sin embargo, más afín con el pensamiento que subyace a la doctrina panteísta, a mi juicio, es preferible hablar de inmanencia, según se desprende del tenor de los siguientes versos: "nada me es ajeno en el mundo / desde que tengo muertos y palabras / eterno soy en mi boca, visitante en mi cuerpo / mi alma me precede, es vuelo sin ser tránsito" (1970: 22, énfasis mío). Inmanencia, no trascendencia, es la posición que sustenta Federico Schopf (en el mencionado prólogo a La compañera, de 1971, cuando comenta Epifanías), y con quien adhiero en este punto:

La poesía de Barquero no es alegoría que degrade lo real como medio de exhibición simbólica de una supuesta trascendencia "metafísica" o "divina". Lo que su escritura quiere hacer palpable alrededor de lo visible es la presencia permanente del origen en lo actual y presente. [...] El origen es trascendente con respecto al momento actual, pero inmanente a la materia y a la especie. [...] El acontecer de la vida es, pues, una incorporación permanente y objetiva a la colectividad y la materia (1971: 18-20).

La inmanencia de ser Uno y Todo al mismo tiempo refleja las debilidades de la razón y el lenguaje para describir y representar dicha percepción de la realidad. Paradoja en literatura o aporía en filosofía, el lenguaje al que 
recurre el hablante barqueriano termina siendo apofático, propio del discurso místico. La apophasis («des-decirse» en griego) es el lenguaje negativo al que acuden los extáticos para referirse a Dios y la muerte, y el concepto de destiempo que utiliza Barquero para compartir su perplejidad en el texto poético implica, precisamente, la negación del tiempo lineal y trascendente, lo cual conlleva una reformulación de la distancia que separa la vida y la muerte. Provoca, en otras palabras, la reconciliación semántica entre lo ántumo y lo póstumo en donde el hablante doma -en los términos de Ariès- a la moderna muerte salvaje, y la hace más cercana y esperanzadora.

En 1992, 22 años después de publicado Epifanías, se agolpa la edición simultánea de tres obras: A deshora, El viejo y el niño y Mujeres de oscuro. Esta última -crucial para esta línea de investigación- es un libro dividido en tres secciones, compuesto en verso, y que, además de reflejar la experiencia del Golpe y el exilio, desarrolla (quizá por eso mismo) latamente el tema de la muerte. Para comprender mejor esta obra debemos recordar que en los inicios del itinerario poético de Barquero (en Enjambre, 1959) el hablante -que está vivo- sólo percibe figuras espectrales; capta y describe en su discurso a muertos y ausentes con los cuales, sin embargo, no mantiene contacto verbal. En El regreso (1961) se produce una evolución en donde el hablante -que se mantiene vivo- inicia un diálogo con su padre muerto y en Mujeres de oscuro (1992), finalmente, el avance tanatológico es total al representar un diálogo de hablantes muertas4. Esta progresión estética representa la paulatina incursión discursiva hacia el misterioso interior de la muerte que se transforma en un inusual lugar de enunciación.

El último libro del corpus metafísico que propongo en este trabajo es $E l$ pan y el vino, publicado en 2008, fecha en que el poeta obtiene el Premio Nacional de Literatura, y dieciséis años después de la entrega de Mujeres de oscuro. Se trata de una composición particular con 27 poemas titulados y otros 27 intercalados sin título, a la manera de una voz en off, como bien describe Naín Nómez, a quien está dedicado el libro. La temática, según el título, gira en torno a una mesa y sus comensales cuya representación escénica es rescatada del episodio evangélico conocido como La Última Cena,

${ }^{4}$ Quizá no sea tan peregrino aventurar que el exilio del poeta empuja a su hablante a cruzar la línea divisoria de la muerte, que antes de 1973 no se había atrevido a franquear, y lo transforma en sujeto escatológico. 
donde Jesús de Nazaret se reúne por última vez con sus discípulos, los doce apóstoles, para compartir el pan y el vino antes de ser crucificado. Sin embargo, la simbología cristiana se ve modificada, a mi juicio, cuando en la mesa representada en el primer poema se recuerda "a un comensal más en quien jamás reparamos” (2008: 7), un fantasma. Ahora bien, más que una mesa o un eventual comedor, en este complejo libro se intenta representar una espacialidad mayor, vagamente definida, que adquiere rasgos metafísicos al contemplar, nuevamente, una mancomunión de vivos y muertos:

Tocó su mano y se removieron las tinieblas como si la dueña de esa mano le sonriera sin rostro [...] Y apretó esa mano con fuerza llamándola en la sombra. Ella le respondió muy lejos, desde un lugar desconocido (2008: 15).

Se repite una vez más, entonces, la reformulación prosopopéyica de la muerte a través de la activa participación fantasmal de personajes muertos que interactúan con los vivos, con lo cual se altera el sentido del tiempo, creando la sensación de una realidad inmanente de corte panteísta. El avance significativo de la propuesta escatológica de Barquero, en esta nueva publicación, radica en que la mancomunión ancestral no queda reducida, como en las obras anteriores, al interior de un clan familiar, ya que en el banquete metafísico participan visitantes y comensales desconocidos que representan, con su anonimato, al resto de la humanidad. De esta manera, en El pan y el vino se universaliza la continuidad del ser a través de figuras espectrales que conviven en una realidad inmanente junto a los vivos, logrando una tonalidad que, acorde a la soteriología cristiana, amplía el alcance esperanzador de la obra barqueriana a un horizonte de la raza humana que sobrepasa los estrechos límites de los antepasados del hablante ${ }^{5}$.

\footnotetext{
${ }^{5}$ En el ensayo que analiza El pan y el vino, Naín Nómez alude al carácter panteísta de esta obra al describir al hablante del texto como "un sujeto que es Uno y es Todo" (2008: 145) y al reconocer una cosmovisión que entiende a la muerte dentro de un proceso de "regeneración continua" (2008: 146). Por otra parte, de forma similar a mi propuesta, su lectura también focaliza a la figura del comensal como "el ser invisible que somos también todos nosotros" (2008: 145), la línea de continuidad de la especie humana. Sugiere, finalmente, que el pan y el vino deben ser considerados como los símbolos de una necesaria experiencia solidaria, afín con el espíritu colectivista que Federico Schopf proponía en su lectura de Epifanías.
} 
En síntesis, y para concluir, la combinación retórica de poesía, religión y filosofía que postula la racionalidad poética de María Zambrano, avalada posteriormente por el pensamiento de Lévinas y Vattimo, permite abordar la propuesta metafísica de la obra poética de Efraín Barquero, al alero de una inspiración soteriológica que aspira a una particular redención de los seres humanos. Se trata, sin duda, de una poética en la que palpita el entusiasmo de la vida, ya que ante el misterio de ultratumba, la redención a la que aspira el hablante barqueriano en el discurso poético se concreta en la esperanzadora continuidad del ser, obtenida mediante la reformulación prosopopéyica de la muerte, en la que se considera a la realidad como una mancomunión ancestral integrada por vivos y muertos. Esta cosmovisión panteísta que rehúye los postulados de una fe trascendente se traduce en una realidad inmanente y común que, si bien inicialmente afecta solamente al clan de los antepasados del hablante, termina finalmente asumiendo un carácter universal.

\section{Bibliografía}

Alegría, Fernando. (1962). La literatura chilena del siglo XX. Santiago: Ediciones Zig-Zag.

Ariès, Philippe. (1992). El hombre ante la muerte. Madrid: Taurus Ediciones.

Barquero, Efraín. (1954). La piedra del pueblo. Santiago: Editorial Alfa. - (1959). Enjambre. Santiago: Ediciones Zig-Zag. . (1960). El pan del hombre. Santiago: Editorial Nascimento. . (1962). Maula. Santiago: Editorial Nascimento. . (1970). Epifanías. Buenos Aires: Editorial Losada. . (1971). Arte de vida. Santiago: Editorial Universitaria. . (2000). Antología. Santiago: LOM Ediciones. . (2008). El pan y el vino. Santiago: LOM Ediciones.

Ferrater, José. (1951). Diccionario de filosofía. Buenos Aires: Editorial Sudamericana.

Heidegger, Martín. (1997). Ser y tiempo. Santiago: Editorial Universitaria. Lévinas, Emmanuel. (1993). Totalidad e infinito. Ensayo sobre la exterioridad. Salamanca: Ediciones Sígueme. 
(2005). Dios, la muerte y el tiempo. Madrid: Ediciones Cátedra.

Nómez, Naín. (2008). "Sobre El pan y el vino de Efraín Barquero: por una liturgia de la solidaridad”, Revista Atenea, 498: 143-151.

Rioseco, Marcelo. (1999). "Panorama de la poesía chilena contemporánea". Revista Litoral, Madrid, Vigésimoctavo año literario, 11-28.

Schopf, Federico. (1971). "Prólogo” en La compañera de Efraín Barquero. Santiago: Editorial Nascimento.

Vattimo, Gianni. (1987). El fin de la modernidad. Barcelona: Editorial Gedisa.

Villegas-Morales, Juan. (1980). Estudios sobre poesía chilena. Santiago: Editorial Nascimento.

Zambrano, María. (1993). Filosofía y poesía. México: Fondo de Cultura Económica. 